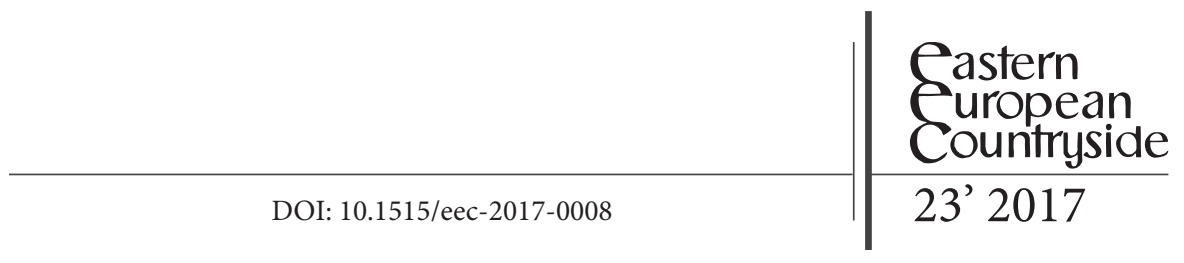

\author{
Dalia Vidickienè
}

\title{
Attractiveness of Rural Areas for Young, Educated Women in Post-Industrial Society
}

\begin{abstract}
Most scholars of rural gender studies do not consider the essential changes in rural economy and life styles, defining rural areas as traditional and conservative. Research is still extremely fragmented into new problems facing the female population in rural areas, those arising from the changes in the lifestyle and the diversified income sources typical of post-industrial rural settlements. This article hence identifies several significant changes in economic and social life in rural areas dealing with the differences between the attractiveness of rural areas as living place for women in the industrial society of the 20th century and the post-industrial society of the 21 st century.

The empirical research presented here proves the relevance of post-industrial theory in a real-world environment by testing the validity of several stereotypical opinions about the motivation to live in Lithuanian rural areas from the position of young well-educated people. The analysis of the opinions of young well-educated women reveals that their motivation is rather different from the perceptions of what was important and motivating for finding good living places; these perceptions have otherwise been pointed out by many gender studies based on the industrial society framework. These findings are a call for implementation of new rural policy measures following the higher incidence of young females as rural entrepreneurs, family farm managers, professionals, and local community leaders.
\end{abstract}

Key words: post-industrial society, industrial stage, gender studies, rural development policy, living place, Lithuania. 


\section{Introduction}

The rural development policies of the EU and other developed countries seek to encourage youth to stay in rural areas because the exodus of young people from rural areas, particularly the exodus of young women, is viewed as threatening the viability and sustainability of these regions: "Young women's rural exodus is perceived as a major problem for rural development, and one of the reasons why the EU has made gender mainstreaming central to RDPs" (Shortall \& Bock 2015: 665).

Gender mainstreaming is the internationally recognised public policy concept of assessing the different implications for women and men of any planned policy action in all areas and on all levels, including legislation and programmes. The concept has been pushed in the United Nations development community from 1985. The idea was formally featured in 1995 at the Fourth World Conference on Women in Beijing, China. It was established as an intergovernmental mandate in the Beijing Declaration and Platform for Action and again in the Economic and Social Council Agreed Conclusions (1997/2).

Gender mainstreaming does not entail developing separate women's projects within work programmes, or even women's components within existing activities in the work programmes. It requires that attention is given to gender perspectives as an integral part of all activities across each programme. This involves making gender perspectives - what women and men do and the resources and decision-making processes to which they have access- more central to all policy development, research, advocacy, development, implementation and monitoring of norms and standards, as well as the planning, implementation and monitoring of projects.

The European Parliament resolution of 12 March 2008 first stated that the out-migration of females in economically active age groups continues to result in a degree of 'masculinisation' of the rural population, with negative consequences for the quality of life of the community and demographic trends. The resolution recommended mainstreaming gender into the rural sector as a key strategy, not only for the promotion of equality between women and men but also for economic growth and sustainable rural development. The recommendations were based on the report of Ch. Klaß (2007), "The situation of women in rural areas of the EU" which focused on a continuing 
out-migration of especially young and well-trained persons. As the majority among those who leave are women, there are negative effects on the social life of that rural area and rural economy. Furthermore, out-migration contributes to the deterioration of the number of 'communal households'.

The institutions of social infrastructure and services of public interests are heavily impaired. Additional to a loss of population, observable lower fertility rates endanger medium to long-term development of these regions. Such situations contribute to a continuing out-migration of especially young and well-trained persons in many places. Rapporteur has asked to give more consideration to gender budgeting with a view to effective governance of rural development programmes and, in particular, better targeting of funding at the specific needs of women in such areas. However, according to the study of B. Bock, a review of literature and scan of policy documents demonstrate that few rural development plans address the gender issues and, generally, only by including some separate projects for women. Little is done to address the systemic features of gender inequality and to realise inclusive developments that address the needs of all social groups (Bock 2015).

In my opinion, one of the reasons why the EU rural development programmes are not effective in using the gender mainstreaming approach is a lack of gender research conducted to provide insight and answers about what issues should be considered when developing a rural and regional policy in line with the evolution of the society. The basis for the academic field of gender studies was laid out in many countries in the 1970s, when women in academia protested against the ways in which academic knowledge production made women invisible and ignored gendered power relations in society. This was the time of intensive industrialisation of the agricultural sector and the findings of the rural gender research highlighted the gender roles relevant to the period of the transition from the agrarian to the industrial society.

However, at the end of the 20st century the European countries started the creation of the post-industrial economy. The transition into the new stage of the economic system evolution should be considered when developing the agenda of rural gender studies because the changes in the economy are changing all spheres of the social life, including the gender issues. The aim of the article is to highlight the new motivation of women to live in postindustrial rural areas with focus on the aspects which may be applicable for the rural development policy. 
Section 1 provides an analysis of the new factors influencing the attractiveness of rural areas as living place with aim to explain the changes in motivation to live in rural areas using post-industrial theory. Section 2 outlines the gap between rural gender research and rural development theory, concluding with suggestions for the development of research. Section 3 illustrates the relevance of post-industrial theory in a real-world environment by findings of the survey of young well-educated Lithuanian people on the validity of several stereotypical opinions about the motivation of women and men to live in the countryside. The paper concludes with discussions towards future research on gender within the broad arena of rural studies and recommendations for rural policy-makers based on the key conceptual and empirical research findings.

\section{New motivation to live in rural areas in post-industrial society}

The situation of rural areas of the developed countries have changed very rapidly over the last two decades. Although most of the world's developed countries entered the industrial era several centuries ago, industrialisation in the agricultural sector has started much more recently. Authors studying the economic history of agriculture argue that large-scale industrialisation of agriculture started only after World War II (Federico 2005). It means that barely half a century ago the lifestyle of agrarian society prevailed in rural areas. Agriculture employed more than 75 percent of the total workforce in traditional agrarian societies, and, as late as 1950, about two-thirds throughout the world. Mechanisation, irrigation, chemicalisation and other industrial technologies have reduced the need for agricultural labour to such an extent that, by the end of the 20th century, the share of people employed in this sector in advanced countries accounted for only 2,5 percent (Federico 2005: 1).

Due to reduced labour demand in the agricultural sector, rural areas in developed countries no longer came to be considered to be an attractive place to live. They were found to offer only limited opportunities to generate other than agricultural income. Moreover, they were found to be too remote and unsafe. Most rural regions suffered an economic decline and they were classified as the poorest in Europe and other OECD countries (OECD 1994; Commission 2004). On top of this problem, in the second half of the 20th 
century the adjectives used to describe a rural area as a place to live included backward and stagnant, as opposed to the urban areas which were referred to as progressive and modern (Hoggart et al. 1995; Williams 1985/1996; Woods 2005). In view of all these factors, following World War II advanced countries have introduced intensive support measures available to rural regions.

However, in the 21st century the attractiveness of a rural area as a place to live is influenced by other factors: 'post-productivist', 'multifunctional', 'reconstructed', 'new rural economy' are all terms used to describe this phenomenon. This article highlights the new factors influencing the motivation to live in rural area using post-industrial theory.

Although the decline of rural areas was pointed out by many authors in the late eighties and early nineties, announced as a general crisis of the rural world, the diversity of situations of being rural is immense. Many rural areas in Europe are now growing faster than urban regions, while others experience a declining situation (Shucksmith et al. 2006). This can be explained by the structural changes in the rural economy. A massive move from agricultural to service occupations opens new opportunities for the rural residents. Now, with the service sector dominating in the economy, the number and impact of negative factors that contributed to the weak level of attractiveness of rural areas in the industrial period is decreasing. The new factors that are key to contributing to the growing attractiveness of countryside as living place are following:

- Livelihood diversification;

- Favourable environment for co-creation;

- Mobility of working place.

At the same time, all new factors create more opportunities to use other advantages of rural living described in the voluminous rural studies: recreational environment, more communal lifestyle, safe neighbourhood, etc.

Livelihood diversification. The allegation is no longer true that rural areas are dominated by farming activities and that those who do not want or fail to engage in agricultural activities have only limited opportunities to generate revenue from other sources. In the 21st century, the rural economy in advanced countries is already highly diversified and farming has ceased to be the main source of income in rural areas. The changes in the economic system and lifestyle have frequently resulted in farmers living intermingled with residents of the countryside who follow nonfarm occupations at urban places of work, even to the extent that farmers are a minority within their 
local rural community. In addition, the farm operator or members of his household may have a nonfarm occupation.

Favourable environment for co-creation. Long-term rural people lack a political voice and rural areas have a low national priority. Since its launch in 1991 by the European Commission as a Community Initiative, the LEADER local development approach has provided rural communities in the European Union with a method for involving local partners in shaping the future development of their area. In the recent history of rural development policy in other countries, there has also been a growing attribution of importance to the involvement of local people in collaborative development and leadership by a set of Participatory Rural Appraisal methods. The rural development programs that provide the opportunity to local people to make their voice heard as a result of their creativity with collaboration becoming a crucial factor increasing the attractiveness of rural areas.

Mobility of working place. In an industrial era, the remoteness of the rural areas was defined as an important weakness. A remote place of residence was thought to prevent people from finding an appealing job, viewed as a factor restricting leisure opportunities. However, in post-industrial society remote living place may be attractive. In recent years, rural areas, especially the most peripheral and remote ones, have become increasingly perceived and identified as spaces of outstanding environmental quality (Figueiredo 2009).

In a service economy, people find it no longer important to live close to the workplace as their activities are often relocated from factories and offices to the work location of their customers or clients. Work from home is increasingly becoming an important source of household revenue as ICT accessibility allows rural residents to work most of their time from home, where they fulfil assignments received from businesses based in urban areas. Cheap vehicles and a good road network have contributed to commuting quite long distances by rural citizens. Consequently, in the post-industrial society human mobility, which manifests itself as a predisposition to find employment and entertainment elsewhere to become central to promoting socio-economic development in rural areas.

All the above factors enhancing the attractiveness of rural living are important, but they are not yet strong enough to dispel myths and overcome the inertia of population in choosing a place of residence. Therefore, the prevention of depopulation in rural areas remains a key challenge of rural 
policy due to the fact that rural areas are less densely populated, where even a slight reduction in population has a tangible impact on the life of the community.

In the post-industrial knowledge society, where the ability to use human resources as knowledge proponents is a key factor to success, depopulation makes rural areas very vulnerable. Therefore, the implementation of rural policy designed to develop the post-industrial society must focus on the main economic resource in this stage of the society development, with the rural population as the holder and manager of knowledge. Being that an increasing share of knowledge conductive to economic success is tacit/non-codified knowledge - which is inextricably linked to the holder (see Polanyi 1966; Nonaka and Takeuchi 1997) - population reduction beyond a critical density in certain rural regions can lead to numerous economic and social issues nationwide. Furthermore, in the context of a knowledge society, it is not only a question of the total population growth but also of their education and workforce skills. Only increased numbers of better skilled entrepreneurial people can lead to creating more added value in rural regions and make them attractive places to live.

\section{Challenges for policy based rural gender research}

Some authors argue that one of the reasons why rural policy measures are not used to address the issue of female population is that there is a lack of data about the division of men and women living and working in rural areas at regional and local level (e.g., Shortall and Bock 2006; Oedl-Wieser 2008; Istenič 2015). However, the task of improving data and information on the lives of rural women is only one of the challenges. In my opinion, the decisions of rural and regional development policy-makers lack a gender policy based on the appropriate research to provide insight and answers about those issues that should be considered when developing a policy. Successful development and implementation of effective measures mostly suffers from insufficiency of research based on the evolutionary approach. An extensive literature in demography, sociology, anthropology and social psychology has documented the transformation of gender roles associated with the process of transferring from pre-industrial (agrarian) society into industrial society. The key challenge facing the gender studies in the beginning of the 21th 
century there is the similar task - the research of rapidly changing gender roles concerned with the process of transferring from industrial society into post-industrial society.

Since the last decade, rural gender research has been expanded, considering the quantity of studies and the scope of issues although, until now, the analysis of rural women's needs are based on the concept of the industrial society. Over the last decades the number of studies has grown a providing theoretical and empirical differentiation between industrial and post-industrial or post-modern rural society, which may be applicable for the rural development policy of the 21st century (e.g., Fekete \& Liptak 2011; Cazorla, De los Ríos \& Salvo 2013; Bruckmeier \& Kopytina 2001; Vidickiené \& Melnikiené 2014).

However, gender issues are not covered in this framework at all. Most rural gender studies do not consider the essential changes in the rural economy and life styles, defining rural areas as traditional and conservative. Rural areas are still contrasted with urban areas as an inferior choice of a place for women to live. For instance, even the newest study maintains, that "policies that persuade women to stay in traditional conservative rural areas may conflict with women's choices to leave, which would afford them greater equality elsewhere" (Shortall \& Bock 2015: 663). There have thus been new insights into the motivation factors both for men and women to live in the rural area within the framework of post-industrial society. These should be a catalyst for re-thinking rural development measures concerning gender aspects at different political levels.

Diversification of the rural economy. The structure of rural economies and diversity of rural livelihoods have received increased attention in discussions about economic aspects of rural development policy during the last three decades. Post-industrial rural societies increasingly serve as residencies for persons with urban-centred sources of livelihood. In comparison with farmers, these people have varying needs in terms of perceptions of the attractiveness of rural areas to live in.

Nonetheless, studies of rural areas attractiveness for women do not draw attention to the fact that the diversification of rural economies is changing social structure of rural communities. In the rural gender studies of the second decade of the 21th century, a rural woman is identified as a farmer (e.g. Sireni 2015; Sabluk 2015). Research into the new problems of the female 
population in rural areas arise from changes in their lifestyle. Moreover, the diversified income sources incident to the post-industrial rural settlements are still extremely fragmented, while gender analysis of rural society beyond farming remains very poor.

On top of these issues, research is mostly based of the concepts of a 'modern' urban and 'traditional' rural community, despite the fact that developed countries have been living in the 'postmodern' society for several decades, with the new characteristics of the society manifesting themselves in both urban and rural areas. Since the early 90s different authors have referred to the emergence of postmodernism, especially in relation to cultural and ideological changes within rural areas (Cloke \& Little 1997; Halfacree 1993; Murdoch \& Pratt 1993; Philo 1993).

Cultural and symbolic dimensions of rurality are then added to socioeconomic criteria, so contributing to a better understanding of rural people, while favouring more accurate approaches and actions in these areas (Cloke 1995; Murdoch \& Pratt 1993; Rinaldi 2004). The rural "becomes a world of social, moral and cultural values in which rural dwellers participate" (Cloke \& Milbourne 1992: 360). This inclusion adds to the extreme topicality of research into attractiveness of rural areas as places to live for women groups with different sources of income.

Favourable environment for co-creation. The service economy provides a fresh look at a stereotypical viewpoint of the industrial era where men should be more committed to their professional careers, entrepreneurship and leadership. According to Michie and Nelson (2006), work expectations, work interests and suitable career options are initially set by the socialisation process and by early perceptions of the structure of job opportunities for women and men. Professional gender segregation is one of the key factors influencing different career possibilities. The principal areas for professional careers during the industrial period were engineering and technology sectors are more appealing for men. For instance, number of studies are guilty of making the "pervasive and durable equation between masculinity and technology" (Faulkner 2000: 3).

In the 21st century, the spheres of activity dealing with the service sector have become important in parallel with engineering and technology. That provides new opportunities and prospects for women, being that businesses relating to the provision of services frequently fail to be a source of inspiration 
for men. Here women are much more proactive and so superior to men because such characteristics as being 'sensitive to the needs of others', 'gentle' or 'loyal' - those which are used describing femininity according to Bem's (1981) widely used masculinity and femininity index - have become the success factors of entrepreneurship and professional career in service sector. The growth of the service sector as a share of the rural economy makes the rural environment more favourable for women.

It is essential to support rural women' leadership not only at the workplace but also in social life to enable vitality of rural community through innovation and collaboration. Given its public forum, leadership has mostly been investigated from a male-dominated perspective (Kramarae \& Spender 2000; Vetter 2010; O'Connor 2010). In contrast, female leadership has been relegated to the private sphere where attention was focused on family and social relation (Vetter 2010: 3).

Male domination is opposed by feminist researchers who have insisted on a leadership that advanced the goals and aspirations of women. Some of the frameworks describe the leadership from feminist perspective and demonstrated how women have conceptualised and practice their leadership roles in ways that differ significantly from most of their male counterparts (e.g. Regan \& Brooks 1995; Sinclair 2014).

The service economy opens up more opportunities for women to evolve the traditional leadership style of top down management slowly into collaborative approach. More recent approaches to rural policy design and implementation have emphasised the co-creation of equitable policy environments by engaging both men and women (Ariztia et al. 2016). Current participatory approaches in rural development should be developed to increase the women's role in the co-creation process getting the findings of a growing family of collaborative approaches into rural development practice, such as like collaborative leadership, participatory leadership, relational leadership, transformational leadership, shared leadership and servant leadership (Bass \& Bass 2009; Ramaswamy \& Ozcan 2014; Williams 2005).

Mobility of workplace. The traditional division of male and female duties in the family is a lower priority in the post-industrial society. According to the stereotype, the duty of a man is to provide for the family while a woman's duty is to use the money earned by her husband sparingly for the household needs and to take care of the children. Therefore, when couples decide where 
they would like to live in the industrial era, they often take into consideration the professional career of the man so the choice of a place to live is closely geographically related to the man's place of work. In the past, although increasing numbers of women have started to enter the labour market, men have earned better salaries than women while their place of work has become the most important factor in choosing the place of residence for their family.

However, new career opportunities have opened for women following a shift in the service sector in the post-industrial economy. Furthermore, there is a growing trend for well-educated women to earn as much as or even more than men. This trend has led to new priorities for women in choosing a place to work and live.

Different rural policy measures can be used to encourage population growth; in particular, educated, qualified people with entrepreneurial skills may be encourage to stay in a rural region to live and work. If the challenge is to increase the numbers of young educated women in rural regions, then rural policy measures should take utmost account of their opinion of the advantages and disadvantages of present day living in rural areas.

\section{The motivation factors for young men and women to live in the post-industrial rural settlements of Lithuania}

Over the last two decades, the economic situation in Lithuanian rural areas has changed substantially. Contrary to popular belief, the rural economy in Lithuania is diverse and increasingly converges with the profile for urban areas. From 2008, the biggest employer in the rural economy has been the service sector. According to the data of the Lithuanian Department of Statistics, employment in the service sector in rural settlements with less than 3000 inhabitants in 2016 accounted for 52.2 percent, but in 2008 through 2016 it had increased by 5.9 percent. However, the total number of working age rural population is decreasing. From 2008 to 2016, the number of women has decreased by 9.5 percent and the number of men by 7.0 percent. Despite the fact that in Lithuanian rural areas there is a shortage of working age women aged 15-64 (in 2016, the number of woman per 1000 men was 913), the share of rural woman employed in the service sector is now bigger and continues to grow more rapidly. In 2008 it was 62.7 percent, while in 2016 increased to 65.4 percent. 
The Lithuanian Institute of Agrarian Economics carried out a study whose purpose was to examine opinions on the attractiveness of living in rural areas in Lithuania. A research was conducted to disclose the motives of young people in choosing a place to live. The criteria in defining of a target group of respondents was based on the concept that "within any given society, postmodern values of gender equality will be most evident among the most secure, that is, the wealthier, better-educated sectors of the public. The less secure strata will prove more traditional in their attitudes toward women" (Inglehart \& Norris 2003: 18).

The research sample included 198 students of the A. Stulginskis University. It is the only institution of higher education and research in Lithuania awarding diplomas and degrees at $\mathrm{PhD}, \mathrm{MSc}$ and $\mathrm{BSc}$ levels in the fields of food sciences, agriculture, forestry, water and land resources management, bioenergy and mechanical engineering, climate change and sustainable use of natural resources. The research surveyed year-3 students in full-time first cycle studies in academic years 2014-2015 and 2015-2016. The research sample was based on a 95 percent confidence level and 7 percent sampling error.

The research topic was very interesting for this group of respondents because, after some months, the students will have to decide where they are going to work and live. The questions were focused on respondent's motivational criteria for determining the decision to take up permanent residence in a rural area and their strategies for organising their economic and social life: i) livelihoods, ii) relationships between living and working place, iii) leadership.

The research findings suggest that Lithuania's rural environment is becoming an attractive place to live for young educated persons. Only 57 percent of the respondents expressed their intentions to live in the rural environment, stating that they had experience of living in the countryside and that they had lived in the rural environment for at least one year. However, upon completion of their studies, 62 percent of the respondents would like to choose rural areas as the place of their permanent residence. This demonstrates that young highly qualified people from urban settings find plenty of advantages in rural living.

The article presents a part of research, which reveals some interesting insights into the motivation factors for men and women to live in the rural area. It is encouraging that the choice of living in the rural environment 
was expressed by a larger percentage of female (67 percent) than male (57 percent) respondents. Furthermore, more women (39 percent) than men (26 percent) are prepared to live in an isolated steading or in a small village with several dozens of houses than in a settlement with several hundreds or thousands of inhabitants. The more detailed analysis showed that this trend is largely due to a new approach amongst young educated women in relation to their opportunities for self-realisation in a rural environment.

The research was focused on the influence of new factors to the position of contemporary young people in relation to the attractiveness of rural areas as living place. The aim was to find out how strongly the following stereotypical gender differences inherent in the industrial society are still expressed amongst young educated people motivated to live in the countryside:

- men want to be business and rural community leaders;

- farming is a male profession;

- professional careers are more important to men;

- men's duties include providing for the family and women's duties include taking care of the children and the household.

The research results have enabled us to catch some important trends in the new motivations of young well-educated women to live in the countryside in terms of livelihood diversification, mobility of workplace and involvement in rural policy decision-making.

\section{Livelihood diversification}

According to Ahl's study (2006), "research articles on women's entrepreneurship reveal, in spite of intentions to the contrary and in spite of inconclusive research results, a tendency to recreate the idea of women as being secondary to men and of women's businesses being of less significance or, at best, as being a complement" (Ahl, 2006, p. 595). According to our survey, farming and rural entrepreneurship have become female gendered concepts for young well-educated Lithuanian women. The ambitions of women and men to run their own business in the rural environment that would be an alternative to farming are almost equal. Here, 16 percent of women and 22 percent of men expect to generate revenues from their own small businesses. 
Analysis of the ways in which gender identities have been constructed in the literature on gender relations and farming published over the two last decades of the 20th century showing that agricultural gender research positions men as head of the family farm enterprise, while women are in the subordinate position of 'farm wives" defined by their dependency, their marriage and family related responsibilities (Brandth 2002). However, our research reveals that young people no longer share the opinion prevailing in the industrial era that farming is a male profession. Instead, 20 percent of the young people responding to the survey will choose farming activities as the main source of income after they complete their studies at the university; here women make up the absolute majority (96 percent). Hence, modern young educated women intend to become farmers even if they do not have a husband or a partner. Meanwhile, 68 percent of women who choose such type of livelihood are single but their parents are engaged in farming activities and they plan to involve their daughters by assigning them functions conforming to their education (agronomy, marketing, finance management, etc.) and to leave their farm to them after they retire.

To a great extent, women find farming attractive because the demand of fresh locally grown organic food in Lithuania has grown notably in parallel with care for food and nutrition safety (Eičaitè 2013; 2016; Eičaitė \& Dabkiené 2014). Many farmers are trying to adapt to this situation and to supply local food for urban households, restaurants, food retailers, etc. The creation of circulation channels between farmers and local food consumers requires new knowledge about innovative organisational models such as organic, permacultural and biodynamic agriculture, as well as ITC tools. Young, welleducated women are hence ready to apply their knowledge at the family farm.

A bigger share of women (67 percent) now wants to implement innovative farming business models based on the short food supply chain and provide consulting, logistic, etc. services for their customers. The men mostly choose an agricultural business model based on traditional supply chain, while only 18 percent of men prefer the farming based on the short food supply chain. These findings are a clear wake-up call for the implementation of new rural policy measures to encourage and nurture a higher incidence of young females as rural entrepreneurs. 


\section{Favourable environment for co-creation}

The rural inhabitants of Lithuania live in an environment that encourages increased participation in decision-making. The success of LEADER in rural areas has formed the opinion that, in contrast to the residents of Lithuanian cities, rural people have more opportunities to have a voice in shaping policy decisions and to become local community leaders (Grunskyte 2014). Respondents designated the greater possibility of influencing the changes in own living environment and becoming a community leader as one of the most important motives for choosing a rural rather than an urban area as a place to live. Previously, this kind of difference between rural and urban areas would only have been important to men. However, in the post-industrial stage this seems to be even slightly more important to young women than to men. Hence, 49 percent of women and 45 percent of men referred to the possibility of becoming a rural community leader and to make a tangible impact on the community as an important stimulus to live in a rural rather than urban environment. This kind of leadership will enable them to influence decisions beyond their family circle and play a very active role in promoting the social and cultural well-being of rural communities.

\section{Mobility of workplace}

Only 8 percent of the woman and 3 percent of the men hope to find a mobile working and living situation. Most of the women who have opted for living in a rural environment and looking for dependent employment (63 percent) said that they were going to find a job first and then find somewhere they would like to live. The percentage of men going to work under an employment contract and who would like to live in close proximity to their workplace accounts for 56 percent of the respondents. Meanwhile, 50 percent of the respondents - with an almost equal share of men ( 55 percent) and women (56 percent) - have expressed their concerns regarding the trade-off between the employability of the husband or wife in their professions and the place they live. The fact that in choosing a permanent place of residence more than 50 percent of young men think about the opportunity of the woman to pursue her professional career demonstrates a changing attitude towards the 
career of women that is taking root among the representatives of the young generation.

In general, the survey results show that the young educated people have new attachments, values and perceptions with regard to rural areas depending on a larger range of social and economic circumstances than some decades ago. The findings are a call for the implementation of new rural policy measures responding to the higher incidence of females as entrepreneurs, family farm managers, professionals and local community leaders. At the same time, rural policy-makers should keep in mind that the economic and social changes in rural areas do not affect all women in the same way, while the key challenge in the post-industrial knowledge society is the differentiation of the support measures according to the level of education of the target group.

\section{Conclusions and future research challenges}

Society is not a static entity, but an ever-changing one. This article suggests that there is a lack of gender studies based on an evolutionary approach to rural development and discourses dealing with differences of concepts of gender roles in industrial and post-industrial stages of rural society's development. The concepts laid out in the literature on rural woman roles published over the second half of the past century are based on the industrial framework. To create an effective support system for women living in rural areas by measures of rural development programmes without reproducing their secondary position would mean changing opinions about gender roles in the family and post-industrial society.

However, most rural support measures are still based on stereotypical concepts of the industrial era without due regard to the fact that educated young people are already oriented towards the lifestyle and values of the postindustrial society. The further development of rural gender studies requires a shift in epistemological position. The challenge for rural gender studies would then be to distinguish new motivations and opportunities afforded to men and women living in the rural areas. To research rural women entrepreneurs, professionals, farmers without reproducing their secondary position would mean challenging the established discursive practices concerning the key success factors of farming, entrepreneurship and leadership and major areas of professional career possibilities. 
The findings presented of the empirical research of the situation in Lithuania reveal a large, unused potential of young well-educated women for change rural areas. The ambitions and plans of women's self-realisation in economic and social life fall in line with the challenges of post-industrial economy and society. In such issues, innovative farming women are more oriented towards the challenges of the service economy in comparison to young men.

The findings of the empirical research suggest following these recommendations for rural policy makers:

- The role of women could be decisive in the implementation of new efficient farming business. It is therefore important to include in rural development programmes measures to support young well-educated women in initiatives for implementing farming based on short food supply chain and enabling them to spread their knowledge to other farmers and local people.

- A significant number of fixed location workers could easily switch to a more flexible approach to working. The support for the development of online workplaces for rural inhabitants may thus become an important tool for attracting new residents to rural areas, especially young women who have parental responsibilities.

- LEADER and other participatory approaches in rural development should be developed to increase the women role in co-creation process together with men.

The empirical research presented here is one of the first attempts to identify the new motivation factors for women to live in post-industrial rural areas. More voluminous studies of how social orders are gendered and of the mechanisms by which this gendering is constructed in post-industrial society would increase the ability of rural gender studies to respond to societal challenges by creating grounds for the integration of a gender mainstreaming concept and a place-based evolutionary approach in rural development policy.

\section{References}

Ahl, H. 2006 'Why research on women entrepreneurs needs new directions', Entrepreneurship Theory and Practice 30(5): 595-621. 
Ariztia, M. T., Jacobs, K. \& Manfre, C. 2016 'Innovative approaches to co-creating equitable policy environments. From collective to co-creative: Experiences implementing gender-responsive local policies' in Global Forum for Rural Advisory Services (GFRAS), Switzerland, pp. 1-6.

Bass, B. M. \& Bass, R. 2009 The Bass Handbook of Leadership: Theory, Research and Managerial Applications, Simon and Schuster.

Bem, S. L. 1981 Bem Sex-Role Inventory, Palo Alto CA: Mind Garden.

Bock B. 2015 'Gender mainstreaming and rural development policy; the trivialisation of rural gender issues', Gender, Place \& Culture 22(5): 731-745.

Bruckmeier, K. \& Kopytina, M. A. 2001 'Post-traditional or post-modern rurality? Cases from East Germany and Russia' in L. Granberg, I. Kovach \& H. Tovey (eds) Europe's Green Ring. Perspectives on Rural Policy and Planning, Aldershot, Burlington, Singapore, Sydney: Ashgate, pp. 167-197.

Brandth, B. 2002 'Gender identity in European family farming: A literature review', Sociologia Ruralis 42(3): 181-200.

Cazorla, A., De los Ríos, I. \& Salvo, M. 2013 'Working With People (WWP)' in Rural Development Projects: a Proposal from Social Learning, Cuadernos de Desarrollo Rural 10(70): 131-157.

Cloke, P. \& Little, J. 1997 Contested Countryside Cultures: Otherness, Marginalisation and Rurality, London: Routledge.

Cloke, P. 1995 '(En)culturing political economy: A life in the day of a 'rural' geographer' in P. Cloke; M. Doel; D. Matless; M. Phillips \& N. Thrift (eds) Writing the Rural: Five Cultural Geographies, London: PCP, pp.19-33.

Cloke, P. \& Milbourne, P. 1992 'Deprivation and lifestyles in rural Wales: II. Rurality and the cultural dimension', Journal of Rural Studies 8: 359-371.

Commission of the European Communities, 2004 Third Report on Economic and Social Cohesion: A New Partnership for Cohesion, Convergence, Competitiveness and Cooperation, Brussels: CEC.

Faulkner, W. 2000 'Dualisms, Hierarchies and Gender in Engineering', Social Studies of Science 30(5): 59-92.

Federico, G. 2005 Feeding the World: An Economic History of Agriculture, 18002000, Princeton University Press.

Fekete, É. \& Liptak, K. 2011 'Postmodern Values in Rural Peripheries', Journal of Settlements and Spatial Planning 2(1): 1-6.

Figueiredo, E. 2009 'One rural, two visions - Environmental issues and images on rural areas in Portugal', European Countryside 1(1): 9-21.

Eičaite, O. 2013 'Promotion of sustainable food consumption', Management Theory and Studies for Rural Business and Infrastructure Development 35(4): 512-521.

Eičaitè, O. 2016 'Lithuanian consumers' views on country of origin labelling for milk and dairy products', Scientific Papers Series Management, Economic Engineering in Agriculture and Rural Development 16(4): 97-102. 
Eičaitė, O. \& Dabkienè, V. 2014 'Lithuanian consumers' attitudes and purchasing behaviour towards domestic livestock products', Scientific Papers Series Management, Economic Engineering in Agriculture and Rural Development 14(4): 73-78.

Halfacree, K. 1993 'Locality and social representation: space, discourse and alternative definitions of the rural', Journal of Rural Studies 9(1): 1-15.

Hoggart, K., Buller, H. \& Black, R. 1995 Rural Europe: Identity and Change, London, New York, Sydney, Auckland: Edward Arnold.

Inglehart, R. \& Norris, P. 2003 Rising Tide: Gender Equality and Cultural Change around the World, Cambridge University Press.

Istenič, M. Č. 2015 'Do rural development programmes promote gender equality on farms? The case of Slovenia, Gender, Place \& Culture 22(5): 670-684.

$\mathrm{Klaß}$, Ch. Report on the situation of women in rural areas of the EU (2007/2117(INI))

Committee on Women's Rights and Gender Equality. Available:

http://www.europarl.europa.eu/sides/getDoc.do?pubRef=-//EP// NONSGML+REPORT+A6-2008-0031+0+DOC+PDF+V0//EN

Kramarae, C. \& Spender, D. 2000 Routledge International Encyclopedia of Women. Global Women's Issues and Knowledg, New York: Routledge.

Michie, S. \& Nelson, D. L. 2006 'Barriers women face in information technology careers: Self-efficacy, passion and gender biases', Women in Management Review 21(1): 10-27.

Murdoch, J. \& Pratt, A. 1993 'Rural studies: Modernism, postmodernism and the 'post-rural', Journal of Rural Studies 9 (4): 411-427.

Nonaka, I. \& Takeuchi, H. 1995 The Knowledge Creating Company. How Japanese Companies Create the Dynamics of Innovation, New York: Oxford University Press.

O'Connor, K. (ed.) 2010 Gender and Women's Leadership: A Reference Handbook, Los Angeles: Sage Publications.

OECD 1994. Creating Rural Indicators for Shaping Territorial Policy. OECD, Paris.

Oedl-Wieser, T. 2008 Rural Gender studies in Austria: State of the Art and Future Strategies, Universität für Bodenkultur Wien, Department für Wirtschafts-und Sozialwiss.

Philo, C. 1993 'Postmodern rural geography? A reply to Murdoch and Pratt', Journal of Rural Studies 9(4): 429-436.

Polanyi, M. 1966 The Tacit Dimension. Chapter 1: Tacit Knowing, Gloucester: Peter Smith (first published Doubleday \& Co 1966, reprinted in 1983).

Ramaswamy, V. \& Ozcan, K. 2014 The Co-creation Paradigm, Stanford University Press.

Regan, H. B. \& Brooks, G. H. 1995 Out of Women's Experience: Creating Relational Leadership, Corwin Press, Inc., 2455 Teller Road, Thousand Oaks, CA. 
Rinaldi, C. 2004 Mediated foodscape. Authenticity, experience and the construction of symbolic rurality. Paper presented at the XI Congress of the International Rural Sociology Association, Trondheim, Norway, July 2004, pp. 25-30.

Sabluk, H. I. 2015 'Social position of woman-peasant on the modern stage of development of rural territories', Ekonomika APK 10(252): 43-58.

Sinclair, A. 2014 'A feminist case for leadership' in J. Damousi, K. Rubenstein \& M. Tomsic (eds) Diversity in Leadership: Australian Women, Past and Present, ANU Press, pp. 17-36.

Shortall, S. \& Bock, B. 2015 'Introduction: rural women in Europe: the impact of place and culture on gender mainstreaming the European Rural Development Programme', Gender, Place \& Culture 22(5): 662-669.

Shortall, S. \& Bock, B. 2006 Rural Gender Relations - Issues and Case Studies, CABI. Shucksmith, M. et al. 2006 First European Quality of Life Survey: Urban-Rural Differences, Luxembourg: Office for Official Publications of the European Communities.

Sireni, M. 2015 'Reinventing rural femininities in the post-productivist Finnish countryside', European Countryside 7(1): 42-56.

Vetter, L. P. 2010 'Overview: Feminist theories of leadership' in K. O'Connor (ed.) Gender and Women's Leadership: A Reference Handbook, London: Sage Publications, pp. 3-10.

Vidickiené, D. \& Melnikienè R. 2014 Kaimo politikos evoliucija [Rural policy evolution], Vilnius: Lietuvos agrarinès ekonomikos institutas.

Williams, R. 1985 'A Problem of Perspective' in G. Crow (ed.) The Sociology of Rural Communities Volume I, pp. 239-243, Cheltenham: Elgar Publishing (reprinted 1996).

Williams, D. 2005 Real Leadership: Helping People and Organizations Face Their Toughest Challenge,. San Francisco: CA: Berrett-Koehler Publishers.

Woods, M. 2005 Rural Geography, London: Sage Publications. 